\title{
Reseña de Parker (2010) La psicología como ideología: contra la disciplina Review of Parker (2010) La psicología como ideología: contra la disciplina
}

\section{Anastasio Ovejero \\ Universidad de Valladolid}

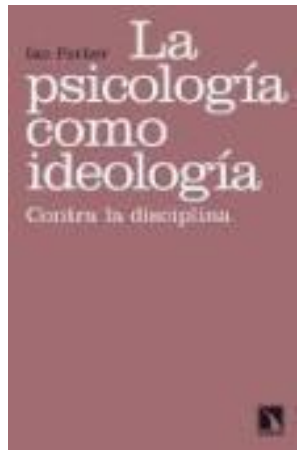

Tengo que comenzar diciendo que estamos ante un libro raro; raro y atrevido. Raro tanto en la forma como en el fondo. $Y$ es raro, en primer lugar, porque en Psicología Social escasean, sobre todo en castellano, libros que, como éste, sean a la vez críticos y radicales: estamos ante un libro mucho más radical que crítico, hasta el punto de que es fuertemente crítico incluso con la propia Psicología Social Crítica. Es raro también a nivel formal: está escrito de una forma un tanto extraña, dado que sus doce capítulos están constituidos por una serie de apartados breves, casi nunca de más de una página y casi siempre de media página que, (permítaseme el símil militar, dado que el libro es fuerte y profundamente militante) a modo de granadas de mano, pretenden ir socavando la línea de flotación de la Psicología y la Psicología Social dominantes, e incluso de las ramas menos dominantes de la Psicología, pero existentes. Ahora bien, tanto por lo poco frecuente de ver libros escritos de esta manera, como porque se hace difícil seguir el hilo conductor que sin duda sí tiene el libro, a mi juicio su principal defecto estriba justamente en la dificultad que entraña su lectura, de forma que probablemente a muchos lectores y lectoras no les resultará fácil seguir el hilo argumental, dificultad que se incrementa por la otra razón fundamental que, a mi modo de ver, hace raro este libro: ninguna de sus páginas son convencionales y además van explícitamente contra corriente, siguiendo siempre la lógica (que hoy día no todo el mundo conoce) tanto del marxismo (con muchas concesiones a autores como Trotski o Gramsci) como de Michel Foucault, de tal manera que, como le pasaba a Wittgenstein, quienes no estén previamente de acuerdo con lan Parker pueden encontrarse con dificultades a la hora de entender lo que dice y sobre todo lo que quiere decir el autor de Manchester.

La lectura puede hacerse, pues muy engorrosa y dificultosa, pues el estilo formal de "granadas de mano", hace difícil seguir el hilo conductor argumental del libro, máxime cuando los argumentos que se esgrimen son de profundo calado y poco conocidos por la mayoría de los ciudadanos e incluso de los propios psicólogos y psicólogas. Y la dificultad de lectura se incrementa aún más a causa de la gran riqueza informativa que incluye Parker (por ejemplo, hay nada menos que 530 notas, 
muchas de ellas con jugosa información, pero que entorpecen la lectura).

Sin embargo, hay algo muy claro en todos y cada uno de los capítulos de este libro y en todas y cada una de sus páginas, que constituye justamente el hijo conductor del libro: no haciendo ninguna distinción entre la Psicología y la Psicología Social, pues ambas vienen a ser lo mismo si lo observamos desde la óptica del papel que están desempeñando en la sociedad capitalista. Ian Parker quiere dejar muy clara una cosa, fundamental en su libro y absolutamente central en toda aproximación crítico-radical a la Psicología: la principal función conservadora de ésta ha consistido en contribuir poderosamente a la psicologización de los problemas sociales, evitando así que salgan a la luz las verdaderas causas de tales problemas y que se señale con el dedo a los verdaderos responsables de los mismos, responsables que no son otros que los poderosos del mundo (por ejemplo, actualmente son quienes dominan y controlan el poder financiero así como las grandes multinacionales armamentistas, farmacéuticas, etc.) así como el sistema de dominación y de explotación del actual sistema capitalista. Estas relaciones capitalistas de explotación y dominación son la principal causa de los problemas de las personas, por lo que no hay que buscarlos dentro de la cabeza o la personalidad de los individuos: la causa de los problemas psicológicos de los individuos no está dentro de ellos. Por el contrario, la insistencia de los psicólogos de todo pelaje a la hora de insistir en que tales problemas se sitúan dentro de las personas y de que, por consiguiente, es dentro de ellas donde hay que intervenir para "curar" tales problemas no hace sino proteger a los verdaderos culpables y sobre todo proteger al sistema capitalista de toda crítica y, por tanto, de toda posibilidad de intentar transformarlo, de intentar cambiar el sistema injusto existente de relaciones sociales capitalistas que son las verdaderas responsables de los problemas de las personas y de los conflictos entre ellas y entre los grupos sociales. Una de las cosas que pretende lan Parker, pues, aunque esto no lo dice explícitamente, es que los psicólogos no seamos imbéciles (parafraseando el dicho, cuando alguien apunta a los problemas sociales sólo los imbéciles miran al dedo que apunta) y alcemos nuestros ojos $-y$ nuestra crítica- a los problemas sociales y no al dedo que los apunta. Porque los problemas sociales no son sino un reflejo de las citadas relaciones de dominación y explotación del sistema capitalista, y por consiguiente son tales relaciones y tal sistema lo que hay que cambiar y no contentarnos con hurgar en el interior de las personas que es lo que hace la Psicología con lo que esta disciplina está cumpliendo una función de preservación y defensa del sistema capitalista. De ahí el título explícito del libro: "La Psicología como ideología", pues se ha constituido a lo largo de más de un siglo en la ideología, individualista y psicologista, del sistema capitalista. Y de ahí también el subtítulo, que muchos pueden considerar, cuando menos, exagerado, lo que significaría que no han habrían entendido su sentido: "Contra la profesión".

Por otra parte, todo lo anterior se entenderá mejor si tenemos en cuenta la distinción fundamental que existe entre Psicología Crítica y Psicología Radical. La primera haría referencia a todas aquellas corrientes de la psicología que pretenden hacer frente a los postulados básicos de la Psicología positivista dominante, mientras que la segunda intenta hacer frente a las funciones conservadoras y de salvaguarda del status quo que está cumpliendo la Psicología. Por consiguiente, puede haber psicólogos críticos pero no radicales, como podría ser el caso de K. Gergen, puede haber psicólogos radicales pero no críticos, como podría ser el caso del asesinado I. MartínBaró, y puede haber autores que son a la vez críticos y radicales, como es el caso de lan Parker, siendo este libro un claro exponente de lo que estoy diciendo. Dado que algunos creemos que, efectivamente, la Psicología dominante ha cumplido y sigue cumpliendo una función ideológica importante de defensa del sistema capitalista y de justificación y hasta de legitimación de sus tan negativos efectos (desigualdades sociales, incremento de la pobreza, hambrunas en el Tercer Mundo, malestar psicológico creciente entre las clases medias de los países desarrollados, etc.), se hace difícil una Psicología radical que no sea crítica, aunque sí es más fácil hacer una Psicología crítica que no sea radical. Como he dicho, lan Parker es las dos cosas a la vez y lo es de una manera altamente coherente. Y este libro es un claro reflejo de ello. Por eso creo que cumple uno de los objetivos que, en mi opinión, debe tener cualquier labor intelectual: dar qué pensar. $Y$ el lector 0 lectora que lea este libro, máxime si es psicó- 
logo o psicóloga, no tendrá más remedio que repensar muchos de los presupuestos sobre los que se ha construido la Psicología a lo largo del último siglo o siglo y medio.

Por todo lo anteriormente dicho, podría pensarse que estamos ante un libro para minorías, ante un libro que sólo pueden leer los psicólogos y psicólogas radicales. Creo que no. Por el contrario, es justamente a los no radicales a los que más útiles les podría ser su lectura. Es más, pienso que a los que sería de gran ayuda y utilidad es justamente a los estudiantes de Psicología, al menos como forma de contrabalancear un poco el excesivo dirigismo ideológico-académico a que son sometidos por parte de los partidarios de la Psicología dominante. Pero la lectura de este libro debería ser inexcusable para los psicólogos, psicólogas, estudiantes de Psicología, estudiantes de otras ramas y público en general que se consideran personas de izquierdas, pues como señala Parker (2010, p. 238), "para las personas embaucadas por la psicología es como si la revolución ya hubiese acontecido, siendo ésta una de las razones que hacen que la psicología sea una parte tan peligrosa y perjudicial de la cultura psicológica de la izquierda..., tenemos que ser muy cautos y no olvidar que la psicología es perjudicial para la izquierda y que cuando ha recurrido a ella ha sufrido una fuerte alteración, hasta el punto de transformar a muchos militantes ávidos por cambiar el mundo en personas ahora convencidas de que no se puede hacer nada por transformarlo".

Porque, digámoslo claro: en contra de lo está Ian Parker es de la Psicología, sea ésta la dominante o la crítica, y sea cuantitativa o cualitativa, de tal forma que llega a escribir (2010, p. 190): “Aún más necesario sería examinar estas nuevas metodologías detalladamente y denunciar cómo las perspectivas interpretativas, del discurso, crítica y la investigación-acción continúan enfangadas en la disciplina de la psicología y de los procesos de psicologización en la sociedad capitalista".

Pero yo pienso que no todos los problemas de las personas provienen de las relaciones de dominación y explotación del sistema capitalista. Por ello, creo que a la vez debería señalarse críticamente la responsabilidad de la Psicología (como un poderoso mecanismo ideología o tal vez como el más poderoso de los existentes) en el mantenimiento y defensa del sistema y la legitimación y justificación de sus nefastas consecuencias, y su potencialidad para la emancipación de los seres humanos, cosa que no hace Parker porque él cree que no puede haber ninguna potencialidad en una psicología que por fuerza tiene que ser individualista y psicologista. Algunos creemos que puede construirse una Psicología que sí sea emancipadora, aunque evidentemente para ello tiene que dejar de ser individualista y psicologista, que es precisamente lo que Parker cree que es imposible. Ciertamente, ello no resulta empresa fácil, a causa de la tal vez inevitable inclinación de la propia Psicología hacia el individualismo, pero tampoco es algo imposible. Una Psicología no individualista, aunque difícil de conseguir, sí podría ser de gran utilidad emancipadora. Es lo que pretende, y a mi juicio está consiguiendo, la Psicología Feminista. En todo caso, incluso para entender cabalmente los presupuestos básicos de la propia Psicología Feminista, la lectura del libro de lan Parker me parece ya no sólo de gran utilidad, sino realmente inexcusable.

\section{Referencias}

Parker, Ian (2010). La psicología como ideología: contra la disciplina. Madrid: Catarata.

\section{ANASTASIO OVEJERO}

Es profesor del Departamento de Psicología de la Universidad de Valladolid.

\section{DIRECCIÓN DE CONTACTO}

tasiovejero@yahoo.es 


\section{FORMATO DE CITACIÓN}

Ovejero, Anastasio (2011). Reseña de Parker (2010) La psicología como ideología: contra la disciplina. Quaderns de Psicologia, 13(1), 117-120. Extraido el [día] de [mes] del [año], de http://www.quadernsdepsicologia.cat/article/view/913 